alone, but that the toxic effects of larger doses are enhanced. That views on therapeutic successes are notoriously apt to be based on faith rather than on fact explains such contradictory opinions; yet methods of clinical trial are available nowadays which overcome these difficulties and yield reliable insight. A few carefully conducted trials, such as that described on p. 13 by H. A. Bowes who was trying to assess the value of azacyclonol ('Frenquel'), are more valuable than any number of uncontrolled clinical impressions. There are many valuable and wellfounded observations in the book, but each article has to be scrutinized for the way in which the conclusions were reached before the reader can accept them as valid. The first seventh of the book contains articles of a somewhat more general nature than the later papers which relate clinical experiences only, but even in this section papers based on clinical impressions only are found side-by-side with others of a more objective nature.

If this book is to guide the practitioner through the labyrinth of neuropharmacology, care must be taken over nomenclature. The table on p. xvii is seriously misleading. Thus it suggests that 'Largactil', 'Megaphen' and 'Thorazine' are different compounds because it lists them alphabetically with other phenothiazines without revealing that they are identical. Even more confusing is the placing of 'Meratran' under the heading 'azacyclonol' and of meprobamate under the heading 'mephenesin', as this suggests that, for example, 'mephenesin' could be used as an alternative and more general name for meprobamate.

The main drugs covered by the book are shown in the title; more than 75 per cent of the material deals with reserpine and chlorpromazine.

Marthe Vogt

\section{SOVIET PSYCHOLOGY}

Psychology in the Soviet Union

Edited with an Introduction by Brian Simon. Translated by J. and M. Ellis, J. McLeish, H. Milne, N. Parsons and others. (International Library of Sociology and Social Reconstruction.) Pp. viii +305. (London: Routledge and Kegan Paul, Ltd., 1957.) 32s. net.

HIS book derives from the work of the Russian physiologist Pavlov, to whom the Western world accords the respect due to a great scientist. It comprises twenty-two papers contributed by contem. porary Soviet psychologists and selected as representative by Prof. A. A. Smirnov and N. A. Menchinskaya of Moscow. Their emphasis is upon human rather than upon animal behaviour, and the studies are frequently in terms of the development of the individual.

The field covered by the nineteen Soviet contributors deals with the principal areas of interest to their Western counterparts. Prof. B. G. Ananiev (Leningrad) deals with problems of perception; Prof. L. V. Zankov (Moscow) with memory, and Prof. E. A. Milerian (Kiev) with attention. The paper on psychopathology by Prof. A. R. Luria (Moscow) suggests close research association of Soviet psychologists with neurophysiologists and psychiatrists. Several papers deal with thinking, apparently a subject of considerable interest to the Russian investigators.
It is on the subject of learning that British and American psychologists have derived most from Pavlov's work : the learning process is now given a central place in the subject-matter of modern experimental psychology. The papers in this field deal with the subject somewhat differently and principally in an educational context, rather than in terms of the more usual technique of the Western psychologist, namely, in the context of animal experiments. Thus, for example, Prof. N. A. Menchinskaya (Moscow) sets out to show how the principles governing learning can be applied to improvement of methods of instruction, and reports experiments on the use of visual techniques in training people to think abstractly in mathematics and elsewhere.

Psychology, presented from the point of view of dialectical materialism, exhibits certain characteristics which merit contrast with Western psychology. The Russian work emerges as heavily experimental ; the method of psychometric measurement that is also prominent in British psychology is noticeably absent. Again, some of the contributors, notably Prof. B. M. Teplov (Moscow), reject the idea current in Western psychological theory that principles and laws are not "immutable" and "objective" parts of Nature but simply tools for making predictions about natural phenomena. In their theory the Russian contributors exhibit a distinct preference for theoretical concepts of a physiological kind. Contemporary Western theorists, by contrast, are sharply divided as to whether basic units of analysis should be physiological or of some other kind (for example, logical or mathematical).

A paper by Prof. A. A. Smirnov (Moscow) assesses achievements and omissions of Soviet work in the period 1953-55. Here and elsewhere, one notes the wide range of complex psychological processes to which Pavlovian concepts and techniques have been applied: these applications will certainly interest British and American investigators. Despite the explicit rejection of the method of introspection by Prof. Teplov, Prof. Smirnov makes a plea for more study of-among other things-the complex problem of differences of mental imagery. $\mathrm{He}$ also makes reference to the need for more study of the history of world psychology, and for more application of the results of completed researches.

A concluding paper gives a Russian assessment of the Fourteenth (Montreal) International Congress of Psychology and indicates that interaction between Western and Soviet psychology is in progress. This book should stimulate more such interaction. The editor, contributors and translators merit our thanks for this valuable and interesting book.

Peter McKellar

\section{MUSCLE PHYSIOLOGY}

\section{Die Muskeltätigkeit}

Versuch einer Biophysik des Quergestreiften Muskels. Von Prof. Eugen Ernst. Pp. 355. (Budapest: Verlag der Ungarischen Akademie der Wissenschaften, Akadémiai Kiadó, 1958.) n.p.

$\mathrm{N}$ the introduction to his book, Prof. Ernst describes 1 the difficulty that he had in deciding to spend a year away from his laboratory in order to write; but there is no doubt that he has done a most admirable and helpful thing, in setting down for us his results and thoughts after forty years work in muscle physiology. It happens all too seldom that a 